\title{
Age of Onset of Bilingualism, Language Use, and the Volitional Subjunctive in Heritage Learners of Spanish
}

\author{
Ariana M. Mikulski, Arizona State University
}

\begin{abstract}
The present study investigates heritage learners' recognition of native-like and nonnative-like mood selection in Spanish volitional constructions along two dimensions: age of onset of bilingualism in English (operationalized as age of arrival) and language use. Thirty-two heritage learners completed a grammaticality judgment (GJ) and an editing task, along with a background questionnaire about family language use, time abroad, and formal Spanish instruction. Participants born in the U.S. or who immigrated before age 6 were defined as early childhood bilinguals; the late childhood bilinguals had arrived in the U.S. between the ages of 6 and 12 . No significant differences in ability to recognize Spanish volitional constructions were found between the early and late bilingual groups, but significant relationships were found between performance and several aspects of language use, including predominant home use of Spanish in the past and multiple trips abroad to hispanophone countries. Results suggest that age of arrival may be an inadequate proxy for age of onset of bilingualism and that language use may be an equally or more important determinant of language abilities.
\end{abstract}

\section{Introduction}

The challenge that the Spanish subjunctive poses for traditional Spanish-as-a-ForeignLanguage (SFL) learners who are native speakers of English has been well documented (Collentine, 2003; Terrell, Baycroft, \& Perrone, 1987). Investigations of L1 Spanish suggest that subjunctive acquisition is a complex process for children as well; although the subjunctive can appear in their speech as early as 2;1 and 2;4 (Hernández-Pina, 1984; López-Ornat, 1994), its use in all of the constructions and contexts in which it is expected often takes several more years (Blake, 1983; PérezLeroux, 1998).

The acquisition of the subjunctive can also be considered for a third group: heritage learners of Spanish. Because it investigates the influence of age of immigration and language use on the ability to recognize the subjunctive, the present study uses the term heritage learner to refer specifically to students of a minority language who have attained some level of proficiency via prior home and/or community exposure (e.g., Valdés, 2001) instead of using it broadly to include all who study their own ancestral language, even if they have had no exposure to it before entering the classroom (e.g., Fishman, 2001). Although the first definition is narrower than the second, it still encompasses great diversity with regard to language experiences and proficiency. For example, whereas some Spanish-as-a-Heritage-Language (SHL) learners have a native-like command of a variant of Spanish (Carreira, 2004), others manifest a combination of native-like and non-native-like characteristics in their Spanish (Carreira, 2004; Lynch, 2003) and resemble SFL learners of varying proficiency levels (Montrul, 2002, 2005). Learners in the latter category likely have non-native-like characteristics in their Spanish because they did not fully acquire some features of the language (incomplete acquisition), or alternatively, lost features 
that they had previously acquired (attrition). Thus, these learners and an investigation of their Spanish language ability can offer insight into the loss as well as the acquisition of the subjunctive. Valdés (2005) has called for research on linguistic differences within heritage learners that go beyond traditional ways of grouping them (e.g., by generation in the United States or schooling). The importance of such research is underscored by current demographic trends. Given that the Latino population continues to grow (Guzmán, 2001; U.S. Census Bureau, 2004) and that Spanish remains the most widely spoken language in the United States after English (Shin \& Bruno, 2003), the number and proportion of SHL learners enrolled in Spanish courses at the K-12 and postsecondary levels may be increasing as well. The present study makes a preliminary contribution by comparing SHL learners' ability to recognize and comprehend the Spanish volitional subjunctive based on their age of arrival and language use.

\section{The Spanish Subjunctive}

The Spanish subjunctive is a verbal mood that appears in adjunct, relative, and complement clauses. Within the latter, it is used in dubitative, affective, and volitional constructions. In dubitative and affective constructions, mood can vary by region and/or semantic-pragmatic factors (e.g., Butt \& Benjamin, 1994; Guitart, 1982). Subjunctive use in volitional constructions (e.g., Los García quieren que su hijo asista a la Universidad de Iowa. 'The Garcías want their son to attend [subjunctive] the University of Iowa.') is consistent and considered obligatory (e.g., Silva-Corvalán, 2001).

An exception to subjunctive use in volitional constructions occurs when the subjects of the matrix and complement clauses in a volitional construction are identical; in a phenomenon known as the subjunctive disjoint reference (SDR) effect (Kempchinsky, 1986), the presence of the subjunctive clause is non-native-like in these instances, and the infinitive is required (e.g., Queremos ir /*que vayamos a México. 'We want to go to Mexico.'). The SDR effect is absent in dubitative constructions and is subject to variation across verbs and regions in affective constructions, so it is most consistently seen in volitional constructions (Kempchinsky, 1986).

The volitional subjunctive can be heard in the daily speech of Spanish speakers from a variety of countries and social classes, particularly because it is used to discuss situations in which one person wants to have influence over another. It is present in indirect commands (e.g., que vayas a tu cuarto 'go [subjunctive] to your room,' which can be interpreted as an abbreviation of quiero que vayas a tu cuarto 'I want you to go [subjunctive] to your room') and some frequently exchanged expressions of politeness (e.g., que tenga buen día 'have [subjunctive] a nice day'). Consequently, it is reasonable to assume that SHL learners have heard the subjunctive in volitional constructions.

\section{Previous Research on the Subjunctive}

Although the subjunctive has been documented in children's speech as early as 2;1 (López-Ornat, 1994) and 2;4 (Hernández-Pina, 1984), it takes several more years for children to use the subjunctive in every context in which it is expected (Blake, 1983; Pérez-Leroux, 1998). Blake's (1983) findings suggest that children acquire the subjunctive first in volitional constructions and adjunct clauses, then in relative 
clauses, and last in dubitative and affective constructions. Children acquire the SDR effect between the ages of 5 and 7 (Padilla-Rivera, 1985), a period that also is marked by fluctuating patterns in mood selection (Blake, 1983) and cognitive development that facilitates use of the subjunctive in relative clauses (Pérez-Leroux, 1998).

Similar to the findings for monolingual children, the acquisition of the subjunctive occurs over many years in child heritage speakers of Spanish. However, studies of this group also have offered evidence of decreasing subjunctive production. In crosssectional subjunctive production data from children in grades K-4, scores were highest for the first graders and declined in each consecutive grade (Merino, 1983). Merino's (1983) longitudinal data suggest that attrition is occurring: the children who were tested again 2 years later had a lower median score for subjunctive production than they had at Time 1. Cross-sectional and longitudinal data also were combined in Silva-Corvalán's (2003) investigation of the Spanish verbal systems of 6 kindergarteners and 1 preschooler. The cross-sectional portion of the study indicated that the children who had subjunctive forms in their repertoire also had the most extensive verbal systems in Spanish and had received more exposure to Spanish; these results suggest that the children who were not producing the subjunctive- -those with less Spanish exposure and more limited verbal systems-were experiencing incomplete acquisition of the subjunctive. The children who had been observed longitudinally produced subjunctive forms at the age of $3 ; 0-3 ; 3$, but no longer had them in their repertoires by age $5 ; 6-5 ; 8$, thereby suggesting that subjunctive attrition may be occurring in child heritage speakers as well.

Research on adult heritage speakers of Spanish has documented intergenerational subjunctive loss. Many of these studies have followed the example of Silva-Corvalán (1991) and categorized participants into three groups: 1) those who immigrated to the U.S. after the age of 11,2 ) those born in the U.S. or who had immigrated before the age of 6 , and 3) those born in the U.S. who have at least one parent who would fit in Group 2. Among Mexican Americans living in Los Angeles, the systems for marking Spanish tense, mood, and aspect became more limited with each successive group (Silva-Corvalán, 1991; 1994; 2001). There was an intergenerational decline in the number of subjunctive tenses present in speakers' repertoires as well as subjunctive use in obligatory and variable contexts. Similar patterns have been reported in studies of Spanish in New York City Puerto Rican (Zentella, 1997) and Miami Cuban (Lynch, 1999) communities. The pattern of decreased subjunctive use in later generations is still present in volitional constructions, but the subjunctive tends to be maintained in these structures to a greater extent than in others (Silva-Corvalán, 2001).

Although few subjunctive studies have been conducted in the SHL classroom, their findings are largely consistent with the general conclusions of the aforementioned research. Examinations of compositions from first-year SHL courses have reported a lack of subjunctive use in volitional as well as other constructions (Colombi, 1997; Teschner, 1981). In comparison to their Mexican classmates, significantly larger percentages of Mexican-American students accepted the indicative in place of the subjunctive on a grammaticality judgment (GJ) task (García \& Terrell, 1977). SHL learners enrolled in SHL and SFL courses scored lower than international students from hispanophone countries on measures of receptive subjunctive abilities in 
obligatory contexts and had difficulties interpreting mood in variable contexts (Montrul, 2007).

The above-mentioned studies have contributed to our knowledge of incomplete acquisition as well as language loss and use among Spanish-English bilinguals in general and their command of the subjunctive in particular, but this research also has limitations. Rather than investigate the specific constructions that require or permit the subjunctive, many have looked only at subjunctive tenses or used a broad distinction between obligatory and variable contexts. Moreover, these studies primarily focused on the informants' production; few have provided information about whether the informants would recognize native-like and non-native-like uses of the subjunctive. Finally, the studies that have considered the diversity in heritage speaker abilities have focused primarily on the variables of generation in the U.S. and age of arrival.

\section{Focus of the Present Study: Age of Onset and Language Use}

Taken together, the previous research offers two possible reasons why the subjunctive may be reduced or absent from SHL learners' verbal repertoires. The first is an early age of onset of bilingualism in English that leads to incomplete acquisition and/or language attrition in Spanish. For SHL learners, increased exposure to English may have resulted in a severe reduction of exposure to Spanish. Because the features of the L1 are not as well-established in younger speakers, early childhood bilinguals may be more susceptible to incomplete acquisition or attrition than older bilinguals. Previous research indicating less subjunctive production among heritage speakers who immigrated before age 6 compared to those who immigrated after age 11 is consistent with this notion if age of onset of bilingualism in English is operationalized as age of arrival in the United States. Research on tense and aspect also has proposed that an early age of onset of bilingualism in English has the potential to cause incomplete acquisition or attrition in Spanish (Montrul, 2002).

The second possible reason concerns language use. SHL learners' home and community language-use situations can vary widely and may impact proficiency: for example, the Spanish abilities of SHL learners who spoke only Spanish outside of the classroom may be quite different from those of SHL learners who spoke English with siblings, parents, and neighbors. In this case, any differences between SHL learners would be a result of differential exposure to English rather than the timing of the first exposure. Previous research on SHL learners has found positive relationships between language use and Spanish proficiency in general (Hakuta \& D'Andrea, 1992) and Spanish grammar (Oh \& Au, 2005), but less is known about the influence of language use on specific features such as the volitional subjunctive.

Onset of bilingualism in English and language use are inter-connected: an early age of onset of bilingualism in English may lead to increased use of English. Consequently, these possible reasons for incomplete acquisition or attrition of the subjunctive are also inter-related. More research is needed to better understand the role of each of these factors. SHL classroom research has the potential to contribute to this field of inquiry. Differences seen between early and late childhood bilinguals in English would highlight the importance of age of onset of bilingualism, or in other words, the timing of the shift from input only in Spanish to input in Spanish and English. On the 
other hand, finding that language use variables explain the diversity of abilities in SHL learners would suggest that the overall quality and quantity of the Spanish input play an essential role in language acquisition and maintenance. The present study is a preliminary exploration of both possible explanations. It focuses on volitional constructions for three reasons: 1) their lack of contextual or dialectal variation, 2) the consistent presence of the SDR effect, and 3) Spanish monolingual children's relatively early acquisition of mood selection in them, which suggests that this feature would be among the last to be lost (e.g., De Bot \& Weltens, 1991). In addition, it examines receptive abilities, which may be retained even in some speakers who do not produce the volitional subjunctive (Silva-Corvalán, 1994). The research questions guiding this study are:

1. Do early and late childhood bilinguals in English differ in their recognition of native-like and non-native-like uses of the Spanish subjunctive in volitional constructions?

2. What elements of language use affect recognition of native-like and non-native-like uses of the Spanish subjunctive in volitional constructions?

\section{Methods}

\section{Instruments}

The present study included four instruments: a grammaticality judgment (GJ) task, an editing task, a multiple-choice cloze passage, and a background questionnaire. Two Spanish instructors who taught at the participating universities but were not involved in the data collection verified that the instruments could be read by students who had completed 2 years of Spanish in their programs. Expected native-like responses for the language tasks were based on a pilot study conducted with 30 native speakers representing 12 hispanophone countries. For an item to remain in the instruments that were administered to the learners, at least $80 \%$ of the pilot participants had to respond to it in a similar manner.

\section{Item Types}

There were four categories of analyzed items on the GJ and editing tasks. Examples taken from the GJ task are provided below.

The first type of item demonstrated native-like use of the subjunctive.

$$
\begin{aligned}
& \text { Esperamos que los Hawks ganen (SUB) el partido de fútbol americano la } \\
& \text { semana que viene. } \\
& \text { 'We hope/expect that the Hawks win the football game next week.' }
\end{aligned}
$$

The second type of item showed use of the infinitive or indicative where the subjunctive is required.

*Marta exige que sus hijos limpian (IND) la cocina después de la cena.

'Marta demands that her children clean the kitchen after dinner.'

(cf. Marta exige que sus hijos limpien la cocina después de la cena.) 
Whereas the first and second types of items tested whether learners recognized where the subjunctive should be used in volitional constructions, the remaining item types assessed learners' recognition of where the subjunctive should not be used in these constructions. In the third type of item, use of the infinitive is native-like because of the SDR effect.
Mis padres prefieren quedarse (INF) en casa los fines de semanas en vez de salir.
'My parents prefer to stay home on the weekends instead of going out.'

The fourth type of item showed non-native-like use of the subjunctive with subject co-reference.

*Deseamos que construyamos (SUB) un garaje al lado de la casa
este verano.
'We want to build a garage next to the house this summer.'
(cf. Deseamos construir un garaje al lado de la casa este verano.)

The GJ task contained items from all four categories, and the editing task contained the first and second types of items.

\section{GJ}

The GJ task asked participants to judge whether utterances could be said in Spanish on a 5-point Likert scale. All items were between 11 and 15 words long and used relatively simple vocabulary (e.g., common verbs, such as ir 'to go' and vivir 'to live'). They were presented in random order.

\section{Editing}

An editing task was included to complement the GJ task, providing an additional source of insight into learners' abilities. It consisted of an article from a health information website that discussed techniques that parents could use to reduce their children's soda consumption. The article contained several instances of the volitional subjunctive and had been rewritten to make the task feasible within a reasonable amount of time and to include more volitional constructions. Examples of non-nativelike mood selection and distracter errors (e.g., modified verb stems, missing prepositions) were also added. After these modifications, the editing task contained 6 examples of native-like use of the subjunctive, 5 examples of non-native-like mood choice, and 15 distracter errors. The article was presented to all participants via a recording in addition to the text because SHL learners acquire spoken Spanish before written Spanish and consequently may find it easier to identify errors in the former.

The sentence below is from the editing task and demonstrates how distracter errors, such as mismatched gender agreement, sometimes occurred in sentences with nativelike mood selection. The feminine opciones 'options' is modified by the masculine otros buenos 'other good,' but the volitional matrix verb evita 'avoid-3sing.' is followed by the subjunctive form pidan 'ask-3pl.SUB.' 
* Si hay otros buenos opciones en la casa, usted evita que sus hijos pidan soda.

'If there are other good options in the house, you avoid having your children ask for soda.'

(cf. Si hay otras buenas...)

\section{Cloze}

Because of inflectional similarities across verb paradigms in the indicative and subjunctive, researchers using GJ tasks cannot determine if certain judgments are made because participants recognize a native-like or non-native-like mood selection, or because they simply confuse their verb paradigms. For example, it is impossible to tell whether students who accept the utterance Algunas universidades requieren que todos los estudiantes vivan en las residencias (dormitorios), 'Some universities require that all students live-SUB in residence halls (dormitories),' do so because the form vivan 'live-3 pl. SUB' functions as a subjunctive form or an indicative form in their verbal repertoires; students who have confused verb paradigms would use -AR endings with the -IR verb vivir 'to live,' which would give the appearance of nonnative-like mood selection. A multiple-choice cloze with deleted present indicative verb forms was used to identify and discard the data of participants who had confused Spanish verb paradigms. Participants had to select a form with the appropriate thematic vowel on 6 of the 7 items to remain in the analysis.

\section{Background Questionnaire}

The background questionnaire included questions about family immigration history, Spanish use at home, time in hispanophone countries, and educational history in regard to Spanish courses.

\section{Participants}

Six third-year Spanish classes at three universities in the Northeast were visited. Some of them were specific SHL courses, and others were intended primarily for SFL learners. All of the participants in the present study had identified themselves as SHL learners on the background questionnaire, indicating that they first had learned Spanish at home.

Thirty-two participants passed the cloze task. The sample was predominantly male (18 males, 13 females, 1 unknown). Most were traditional college students who previously had studied Spanish at the secondary and/or postsecondary levels. They traced their backgrounds to 12 different hispanophone countries; the most frequently reported heritages were Mexican (10 students), Dominican (5), and Puerto Rican (4). Table 1 shows age of arrival in the U.S. for the sample. Nineteen participants had been born in the U.S. (Table 1). Nevertheless, experience abroad was common within the group: twenty-three had spent over 2 weeks in a hispanophone country. 
Table 1. Participant Age of Arrival (in Years) in the United States (Excluding Puerto Rico)

\begin{tabular}{ll}
\hline Age of arrival & Number of learners \\
\hline Born in the United States & 19 \\
3 & 2 \\
4 & 1 \\
5 & 2 \\
6 & 2 \\
7 & 1 \\
8 & 1 \\
10 & 1 \\
12 & 1 \\
17 & 1 \\
18 & 1 \\
Total & 32 \\
\hline
\end{tabular}

\section{Procedure}

Data were collected during 30 minutes of class time at the beginning of the semester to limit the exposure that participants would have had to very recent instruction in the subjunctive. Two versions of the instrument packet were distributed at random to minimize task effect; they contained the GJ task and cloze in alternating orders. Both versions presented the editing task first and the background questionnaire last, which allowed the participants to listen to the recording of the editing task article as a group and complete the questionnaire after the language tasks.

The participants were asked to skip ahead to the background questionnaire when there were 5 minutes left in the administration period so that they could identify themselves as SHL or SFL learners. They were informed that they could return to any skipped items on the language tasks if they had time after completing the background questionnaire.

\section{Analysis}

Scoring

Participants received 1 point each time they provided a native-like response. On the GJ task, a point was awarded for each native-like judgment. Two types of native-like responses were possible on the editing task: changing an indicative form to the subjunctive in the constructions where the subjunctive was expected or retaining a native-like use of the subjunctive. Because the present study focused on mood choice, other modifications made to the verbs (e.g., changes in person/number) did not affect participant scores.

\section{Early and Late Childhood Bilinguals}

The age of 6 was set as the boundary between early and late childhood bilinguals in the present study for two reasons. First, use of the subjunctive has been observed at early ages, particularly in volitional constructions (Blake, 1983). Children over the age of 6 , therefore, would be likely to have acquired the volitional subjunctive. Second, this age fit the distribution of the sample because there were many participants who were born in the United States or who had immigrated in early childhood (see Table 1). In keeping with earlier research (e.g., Silva-Corvalán, 1991), 
age of onset of bilingualism in English was operationalized as age of arrival in the U.S.

Using the boundary age of 6, 24 of the participants were categorized as early childhood bilinguals. Of the remaining 8 participants, 6 were placed in the late childhood bilingual group because they had arrived in the U.S. between the ages of 6 and 12. The remaining 2 SHL learners immigrated to the U.S. in their late teens and consequently were categorized as young adult bilinguals in English. Because the number of participants in this group was so small, it was not feasible to include them as a group in any inferential statistical analyses. Consequently, their means are presented in the results section, but are not included in any discussion of statistical significance.

\section{Language Use}

Table 2 presents the language use variables, which were based upon participants' responses to background questionnaire items about family language use, formal Spanish instruction, and time spent in hispanophone countries. A series of categorical variables measuring previous and current language use with the family was created from answers to a question that asked, "How much Spanish was spoken in your family when you were a child? Did this ever change? Explain.” The referent categories were past and current predominant use of English with the family. Twentytwo participants reported that Spanish had been the predominant language in their home during childhood, and 15 reported current predominant use of Spanish with their families (Table 2).

Table 2. Participant Language Use

\begin{tabular}{ll}
\hline Language use variable & Number of learners \\
\hline Predominant family language use & 22 \\
Previously Spanish & 9 \\
Previously English & 15 \\
Currently Spanish & 16 \\
Currently English & 1 \\
Missing family language use & \\
Spanish instruction & 20 \\
Elementary/middle & 10 \\
No elementary/middle & 2 \\
Missing elementary/middle & 26 \\
High school & 4 \\
No high school & 2 \\
Missing high school & 22 \\
Post-secondary & 8 \\
No post-secondary & 2 \\
Missing post-secondary & 8 \\
2 weeks or less & 6 \\
One trip over 2 weeks & 17 \\
Over 2 weeks: several trips & 1 \\
Missing time abroad &
\end{tabular}


With regard to educational experiences, participants reported how long they had studied Spanish at the elementary/middle, high school, and postsecondary levels (not counting the current semester). Twenty, 26, and 22 participants indicated that they had taken Spanish courses at these respective levels (Table 2). This information was used to create a series of dummy variables for having received formal Spanish instruction. For each level of education, the referent category was no Spanish instruction. Participants who attended school in a hispanophone country were included as having received formal Spanish instruction at that time.

Participants were asked if they had spent over 2 weeks in a hispanophone country. Those who responded affirmatively reported where and when they had traveled, along with the length of their stays. The referent category was spending less than 2 weeks abroad. Those who reported more time abroad were placed into two groups: those who had been abroad once and those who had been abroad several times. The latter group was the largest, consisting of 17 participants (Table 2).

\section{Missing Data}

Six participants had missing observations in their language task data. One did not make any markings on the passage in the editing task. The others had missing observations on the GJ task, primarily on the last items. Thus, it appears that lack of time to complete the instrument was the principal reason why there were missing data. Missing data is a common problem in the social sciences that can be accounted for by discarding the data that have missing observations, which is known as listwise deletion, or assigning a value to those observations (Allison, 2002). Because each missing data technique has benefits and drawbacks, early and late childhood bilingual performance was compared using three techniques: listwise deletion, scoring every missing response as a non-native-like answer (i.e., assigning a value of 0 points to each missing response), and multiple imputation. This paper presents the results of the regressions conducted using multiple imputation. Missing responses were scored as non-native-like for the measures of dispersion and analyses that explored the role of language use variables because this technique included all participants and provided consistent score calculations.

\section{Quantitative Analyses}

SHL learners at all three institutions were pooled into a single sample because previous analyses with this data did not show institution effects (Mikulski, forthcoming). Early and late childhood bilingual scores on individual tasks and the combined scores (editing and GJ) were compared using difference in means tests (i.e., t-tests) and linear regressions. The former were used for the analyses with listwise deletion and scoring non-responses as non-native-like, whereas the latter were used with multiple imputation.

The percentage of early and late childhood bilinguals who gave a native-like response to each item was compared using a series of difference in proportions tests. Because of the focus on item-level differences, the analysis for each individual item only included those who answered it. 
A series of multivariate linear regressions was conducted to examine the relationship between participants' individual task and combined scores and language use variables. The $\alpha$ was set to $\mathrm{p}<0.05$ for all analyses.

\section{Results}

Table 3 presents the range and standard distribution of the individual task and combined scores for the entire sample. Figure 1 displays the distribution of combined scores. The participants demonstrated substantial variability in their performance.

Table 3. Range of Scores (Standard Deviations Given in Parentheses)

\begin{tabular}{lll}
\hline Task & Points possible & Range \\
\hline Editing & 11 & $0-11(2.5)$ \\
GJ & 13 & $3-13(3.1)$ \\
Combined score & 24 & $3-24(5.1)$ \\
\hline
\end{tabular}

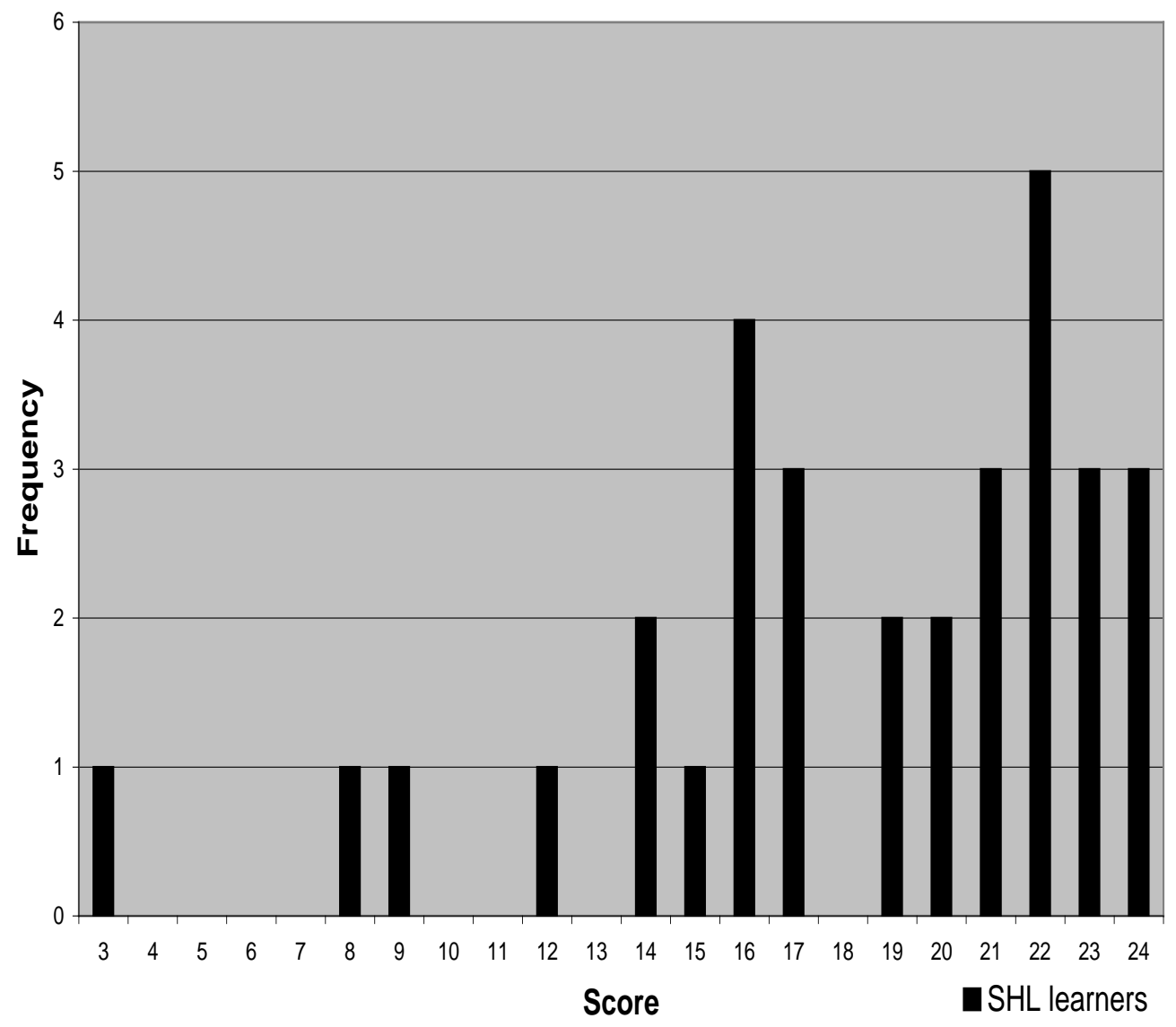

Figure 1. Distribution of combined scores

When the sample was divided into groups based on age of arrival, the analyses showed no significant differences between early childhood and late childhood bilinguals in English (p-values ranged from 0.723 to 0.808). ${ }^{1,2}$ Table 4 presents the mean scores for these groups, along with the mean scores for the young adult 
bilinguals. There was less than one point separating the average scores for the early and late childhood bilingual groups on the individual task and combined scores. The young adult bilinguals had a lower score than the other groups on the editing task but had higher GJ and combined scores. ${ }^{3}$ Similarities across groups were also seen at the individual item level. No significant differences were found between the early and late childhood bilinguals on any of the individual items on either task (p-values ranged from 0.314 to 1.000 on the editing items, and from 0.259 to 1.000 on the GJ items). The percentage of young adult bilinguals who responded to an item in a native-like manner often was identical to the percentage of late childhood bilinguals who had done the same. For example, all of the young adult and late childhood bilinguals rejected the following utterance.

*Carlos quiere que su hermana ir a la fiesta de cumpleaños de su amigo.

'Carlos wants his sister to go to his friend's birthday party.'

(cf. Carlos quiere que su hermana vaya a la fiesta de cumpleaños de su amigo.)

The percentage of early childhood bilinguals who did the same, although lower at $82 \%$, was still quite high. Moreover, even though this item had the lowest p-value obtained for any individual item, the difference between early and late childhood bilinguals was not statistically significant $(\mathrm{p}=0.259)$.

Table 4. Average Task Scores for Early Childhood, Late Childhood, and Young Adult Bilinguals (Standard Errors Are in Parentheses)

\begin{tabular}{llllll}
\hline Task & $\begin{array}{l}\text { Points } \\
\text { possible }\end{array}$ & $\begin{array}{l}\text { Early } \\
\text { childhood } \\
\text { bilinguals } \\
\text { (n= 24) }\end{array}$ & $\begin{array}{l}\text { Late } \\
\text { childhood } \\
\text { bilinguals } \\
\text { (n= 6) }\end{array}$ & $\begin{array}{l}\text { Young } \\
\text { adult } \\
\text { bilinguals }\end{array}$ & P-value \\
(n= 2) & \\
\hline Editing & 11 & $8.8(0.4)$ & $9.0(1.0)$ & 8.5 & 0.723 \\
GJ & 13 & $9.8(0.6)$ & $10.3(1.3)$ & 11 & 0.808 \\
Combined & 24 & $18.6(0.9)$ & $19.3(2.0)$ & 19.5 & 0.725 \\
score & & & & & \\
(editing + & & & & & \\
GJ) & & & & & \\
\hline
\end{tabular}

${ }^{\mathrm{a}}$ No standard errors are given for the young adult bilinguals because they were not included in the statistical analyses.

In contrast, the multivariate analyses show that language use variables help explain variance in learner performance. Table 5 presents R-squares as well as the coefficients and standard errors for the regression of individual task and combined scores on language use variables. The R-squares for these analyses are relatively high, ranging from 0.397 for the GJ task to 0.704 for the editing task. In addition, some individual variables significantly affected scores. Predominant use of Spanish at home in the past and multiple visits to hispanophone countries were positively associated with editing task scores $(\mathrm{p}=0.012$ and $\mathrm{p}=0.011$, respectively). Formal Spanish instruction at the elementary and middle school levels was negatively associated with editing task scores $(\mathrm{p}=0.025)$. Finally, the combined score model showed a significant positive association between multiple visits abroad and increased scores $(\mathrm{p}=0.031)$. No language use variables were significantly associated with the GJ task scores. ${ }^{4}$ 
Table 5. Coefficients for the Regression of Scores on Language Use Variables ${ }^{a}$

\begin{tabular}{|c|c|c|c|c|c|c|}
\hline \multirow[b]{2}{*}{$\begin{array}{l}\text { Independent } \\
\text { variables }\end{array}$} & \multicolumn{2}{|c|}{ Combined score } & \multicolumn{2}{|c|}{ GJ score } & \multicolumn{2}{|c|}{ Editing score } \\
\hline & Coefficient & $\begin{array}{l}\text { Standard } \\
\text { error }\end{array}$ & Coefficient & $\begin{array}{l}\text { Standard } \\
\text { error }\end{array}$ & Coefficient & $\begin{array}{l}\text { Standard } \\
\text { error }\end{array}$ \\
\hline \multicolumn{7}{|l|}{ Family } \\
\hline \multicolumn{7}{|l|}{ language use } \\
\hline $\begin{array}{l}\text { Previously } \\
\text { Spanish }\end{array}$ & 3.911 & 1.928 & 1.726 & 1.411 & $2.186^{*}$ & 0.798 \\
\hline $\begin{array}{l}\text { Currently } \\
\text { Spanish }\end{array}$ & 2.427 & 1.653 & 1.299 & 1.210 & 1.127 & 0.684 \\
\hline \multicolumn{7}{|l|}{$\begin{array}{l}\text { Spanish } \\
\text { instruction }\end{array}$} \\
\hline $\begin{array}{l}\text { Elementary/ } \\
\text { middle }\end{array}$ & -3.165 & 1.695 & -1.481 & 1.240 & $-1.684^{*}$ & 0.701 \\
\hline $\begin{array}{l}\text { Missing } \\
\text { elementary/ } \\
\text { middle }\end{array}$ & -0.393 & 6.126 & -1.806 & 4.484 & 1.413 & 2.536 \\
\hline High school & 1.955 & 2.222 & 0.968 & 1.626 & 0.987 & 0.920 \\
\hline $\begin{array}{l}\text { Missing high } \\
\text { school }\end{array}$ & 8.840 & 4.986 & 6.666 & 3.649 & 2.173 & 2.063 \\
\hline $\begin{array}{l}\text { Post- } \\
\text { secondary }\end{array}$ & 1.910 & 1.852 & 1.796 & 1.355 & 0.113 & 0.767 \\
\hline \multicolumn{7}{|l|}{ Time abroad } \\
\hline $\begin{array}{l}\text { One trip over } \\
2 \text { weeks }\end{array}$ & 2.228 & 2.496 & 2.325 & 1.827 & -0.098 & 1.033 \\
\hline Multiple trips & $4.241^{*}$ & 1.838 & 2.143 & 1.345 & $2.099 *$ & 0.761 \\
\hline Constant & $10.325^{* *}$ & 3.102 & $4.814^{*}$ & 2.271 & $5.511 * *$ & 1.284 \\
\hline $\begin{array}{l}\text { Number of } \\
\text { cases }\end{array}$ & 32 & & 32 & & 32 & \\
\hline R-squared & 0.582 & & 0.397 & & 0.704 & \\
\hline
\end{tabular}

${ }^{\mathrm{a}}$ The categories for missing family language use, missing post-secondary Spanish instruction, and missing time abroad were dropped from the analyses because they contained only one participant.

$* \mathrm{p}<0.05$

$* * \mathrm{p}<0.01$

\section{Discussion and Conclusion}

The first research question in this study asked about differences in volitional subjunctive recognition between SHL learners who were early and late childhood bilinguals in English. No significant differences were found between these two groups. In some ways, these results are a departure from previous research on heritage speakers. Montrul (2002) found that those who acquired English between the ages of 8 and 12 performed more like Spanish monolinguals with regard to tense/aspect than those who were simultaneous bilinguals or acquired English in early childhood. Nevertheless, there are potential explanations for the similarities found between early and late childhood bilinguals in the present study. One possibility is that the volitional subjunctive is acquired so early that differences between early and late bilinguals on this feature do not exist. Another explanation for the results of the present study is that 
age of arrival in the United States may not be a suitable measure of age of onset of bilingualism among heritage speakers of Spanish. A speaker's exposure to English is determined by the nature of language use in the home and community. For example, some SHL learners who were born in the United States or who immigrated during early childhood may have used only Spanish at home or in the community and consequently may not have been exposed to English until they began school. Such situations are not accurately represented when age of arrival in the United States is used to determine one's status as an early or late childhood bilingual. Perhaps the number of participants whose age of onset of bilingualism in English did not match their age of arrival was enough to conceal any differences that existed between early and late childhood bilinguals. Future research should ask questions that allow for more precise estimation of age of onset of bilingualism instead of using age of arrival in the United States as a proxy for this measure.

The second research question inquired about which elements of language use affect recognition of native-like and non-native-like uses of the volitional subjunctive. The multivariate analyses indicated that the language use variables of family language use, formal Spanish instruction, and time abroad in hispanophone countries explained a substantial amount of the variance in scores. This supports the notion that overall quantity and quality of input play important roles in predicting learner performance. Several variables were significantly associated with scores. The finding that predominant use of Spanish with family in the past was associated with higher editing scores suggests that family Spanish use provided the exposure to the volitional subjunctive necessary for the participants to acquire and maintain it. The relationship between multiple trips abroad and increased editing and combined scores implies that these trips provide similar opportunities for SHL learners. However, the negative relationship between elementary/middle school formal Spanish instruction and editing scores is more difficult to interpret because it was the opposite of what was expected. The small sample size and variation in quantity and quality of elementary and middle school Spanish instruction may have affected these results. Nevertheless, taken together, the results of the multivariate analyses call for further exploration of which language experiences support language maintenance the most and whether such experiences are more accurate predictors of proficiency than age of onset of bilingualism.

Although the research questions treated them separately, age of onset of bilingualism and language use are inter-related. For those who did not learn English in early childhood, Spanish was the only home language for several years. In addition, some would have received formal Spanish instruction in the elementary grades because they were attending school in a hispanophone country. That experience would have given them many opportunities to see that the subjunctive and indicative forms are spelled differently, and their teachers may have corrected verbal mood on assignments, which in turn also may have provided reinforcement of the use of the subjunctive in volitional constructions. At the same time, however, it is possible that a strong Spanish literacy environment in the home and formal Spanish instruction in U.S. schools also would provide support that would help maintain this feature. Future research should consider age of onset of bilingualism and language use variables together, either through multivariate analyses or qualitative research. In particular, studies that include literacy and formal instruction experiences as language use 
variables have the potential to provide insights into the connections between age of onset of bilingualism, language use, and proficiency.

The creation of categorical language use variables for use in multivariate analyses should also be addressed in future research. In the present study, the content of openended questionnaire responses was analyzed to derive the categories. Alternatively, questionnaires could include closed-ended items (e.g., multiple-choice questions about family language use at different times in the participant's life), but the creation of such questions will also require a consideration of how to operationalize language use variables. Discussion of this issue will help researchers investigate the influence of language use on participants' language abilities more effectively.

Future research that categorizes SHL learners as early or late childhood bilinguals in English can also explore different boundary ages. For example, in the case of the volitional subjunctive, it is possible that differences between early and late childhood bilinguals can be found using an age lower than 6 , given that this feature appears in the speech of very young children (Blake, 1983; Hernández-Pina, 1984).

Alternatively, research focused solely on the SDR effect can use a higher boundary age to ensure that all of the late bilinguals have been exposed only to Spanish when it is typically acquired. The small sample size in the present study limited the number of analyses that could be performed using other boundary ages. ${ }^{5}$

Although the early childhood, late childhood, and young bilingual groups attained relatively high scores, there was a great deal of variation in scores, more so than was seen in SFL learner peers (Mikulski, forthcoming). Given that SHL courses are not consistently offered at the post-secondary level and programs vary in structure (Valdés, Fishman, Chávez, \& Pérez, 2006), SHL classrooms where students have diverse abilities may be the norm. Future research should endeavor to understand this variation and subsequently develop best practices for SHL courses at all levels, as well as courses that serve a combination of SHL and SFL students.

The results of the present study also have implications for institutions that completely or partially rely on questions about language experience for placement in their SHL sequences. The significant relationships found between performance and several language use variables, along with the lack of significant differences between early and late childhood bilinguals, imply that questions about family language use, formal Spanish instruction, and time abroad in hispanophone countries will be better predictors of proficiency than a single item about age of arrival. Nevertheless, more research on the relationship between language experience and use or recognition of various language features as well as SHL placement procedures must be conducted before concrete recommendations may be offered.

The present study is a preliminary exploration of how age of onset of bilingualism and language use affect receptive volitional subjunctive abilities. It elicited responses only to written data and had a small sample size. Larger quantitative studies will increase statistical power and allow for additional analyses of age of onset of bilingualism: different boundary ages can be used, the young adult bilinguals can be included as a group in inferential analyses, and age can be entered as a variable in multivariate 
analyses. The inclusion of both receptive and productive measures will improve our understanding of the relationship between recognition of native-like mood selection and its production in speech or writing. In addition, it would be beneficial to compare SHL abilities across modalities. Because SHL learners typically have more experience with spoken language than with written language, they may be more successful at detecting spoken utterances that sound non-native-like to them than written utterances that look non-native-like to them.

The increasing number of heritage speakers in the United States highlights the importance of examining age and environmental effects in heritage language acquisition. One approach is to measure how age of onset of bilingualism and language use affect SHL learners' abilities in various features of Spanish. Further research in this area has the potential to contribute to our knowledge of SLA, simultaneous bilingual language acquisition, and language loss.

\section{Acknowledgements}

This paper was based on the author's dissertation. She would like to thank the participants and their instructors, as well as the members of her committee: L. Kathy Heilenman, Judith Liskin-Gasparro, Paula Kempchinsky, Carol Severino, and Roumyana Slabakova. The author is also grateful to Barbara Lafford and Jeff MacSwan, who provided helpful feedback on an earlier draft of the paper, and the anonymous reviewers, who offered many insightful suggestions.

\section{References}

Allison, P. D. (2002). Missing data. Thousand Oaks: Sage.

Blake, R. J. (1983). Mood selection among Spanish-speaking children, ages 4 to 12. The Bilingual Review/La revista bilingue, 10(1), 21-32.

Butt, J., \& Benjamin, B. (1994). A new reference grammar of modern Spanish (2nd ed.). Lincolnwood: NTC Publishing Group.

Carreira, M. M. (2004). Seeking explanatory adequacy: A dual approach to understanding the term "heritage language learner." Heritage Language Journal, 2(1). Available from http://www.heritagelanguages.org.

Collentine, J. (2003). Development of subjunctive and complex-syntactic abilities among foreign language learners of Spanish. In B. Lafford \& R. Salaberry (Eds.), Studies in Spanish second language acquisition: The state of the science (pp. 7497). Washington: Georgetown University Press.

Colombi, M. C. (1997). Perfil del discurso escrito en textos de hispanohablantes: Teoría y práctica. In M. C. Colombi \& F. X. Alarcón (Eds.), La enseñanza del español a hispanohablantes: Praxis y teoría (pp. 175-189). Boston: Houghton Mifflin.

De Bot, K., \& Weltens, B. (1991). Recapitulation, regression, and language loss. In H. W. Seliger \& R. M. Vago (Eds.), First language attrition (pp. 31-51). Cambridge: Cambridge University Press.

Fishman, J. A. (2001). 300-plus years of heritage language education in the United States. In J. Kreeft Peyton, D. A. Ranard \& S. McGinnis (Eds.), Heritage languages in America: Preserving a national resource (pp. 207-228). McHenry, IL: The Center for Applied Linguistics and Delta Systems. 
García, M. E., \& Terrell, T. (1977). Is the use of mood in Spanish subject to variable constraints? In M. P. Hagiwara (Ed.), Studies in Romance linguistics: Proceedings of the fifth linguistic symposium on Romance languages (pp. 214226). Rowley, MA: Newbury House.

Guitart, J. M. (1982). On the use of the Spanish subjunctive among Spanish-English bilinguals. Word, 33(1-2), 59-67.

Guzmán, B. (2001). The Hispanic Population: Census 2000 Brief. Washington, DC: U.S. Census Bureau. Retrieved from http://www.census.gov/prod/2001pubs/c2kbr01-3.pdf

Hakuta, K., \& D'Andrea, D. (1992). Some properties of bilingual maintenance and loss in Mexican background high-school students. Applied Linguistics, 13(1), 7299.

Hernández-Pina, F. (1984). Teorías psico-sociolingüísticas y su aplicación a la adquisición del español como lengua materna. Madrid: Siglo XXI editores.

Kempchinsky, P. (1986). Romance subjunctive clauses and logical form. Unpublished doctoral dissertation, University of California - Los Angeles.

López-Ornat, S. (1994). La adquisición de la lengua española. Madrid: Siglo XXI.

Lynch, A. (1999). The subjunctive in Miami Cuban Spanish: Bilingualism, contact, and language variability. Unpublished doctoral dissertation, University of Minnesota.

Lynch, A. (2003). The relationship between second and heritage language acquisition: Notes on research and theory building. Heritage Language Journal, 1(1). Available from http://www.heritagelanguages.org/.

Merino, B. J. (1983). Language loss in bilingual Chicano children. Journal of Applied Developmental Psychology, 4(3), 277-294.

Mikulski, A. M. (forthcoming). Receptive volitional subjunctive abilities in heritage and traditional FL learners of Spanish. Modern Language Journal.

Montrul, S. A. (2002). Incomplete acquisition and attrition of Spanish tense/aspect distinctions in adult bilinguals. Bilingualism: Language and Cognition, 5(1), 3968.

Montrul, S. A. (2005). Second language acquisition and first language loss in adult early bilinguals: Exploring some differences and similarities. Second Language Research, 21(3), 199-249.

Montrul, S. A. (2007). Interpreting mood distinctions in Spanish as a heritage language. In K. Potowski \& R. Cameron (Eds.), Spanish in contact: Policy, social, and linguistic inquiries (pp. 23-40). Amsterdam: John Benjamins.

Oh, J. S., \& Au, T. K.-f. (2005). Learning Spanish as a heritage language: The role of sociocultural background variables. Language, Culture, and Curriculum, 18(3), 229-241.

Padilla-Rivera, J. (1985). On the definition of binding domains in Spanish: The roles of the binding theory module and the lexicon. Unpublished doctoral dissertation, Cornell University.

Perez-Leroux, A. T. (1998). The acquisition of mood selection in Spanish relative clauses. Journal of Child Language, 25(3), 585-604.

Shin, H. B., \& Bruno, R. (2003). Language use and English-speaking ability: 2000. In U. S. Census Bureau (Ed.), Census 2000 Brief. Washington: U.S. Census Bureau. Retrieved from http://www.census.gov/prod/2003pubs/c2kbr-29.pdf 
Silva-Corvalán, C. (1991). Spanish language attrition in a contact situation with English. In H. W. Selinger \& R. M. Vago (Eds.), First language attrition (pp. 151-171). Cambridge: Cambridge University Press.

Silva-Corvalán, C. (1994). Language contact and change: Spanish in Los Angeles. Oxford: Oxford University Press.

Silva-Corvalán, C. (2001). Sociolingüística y pragmática del español. Washington, DC: Georgetown University Press.

Silva-Corvalán, C. (2003). Linguistic consequences of reduced input in bilingual first language acquisition. In S. Montrul \& F. Ordóñez (Eds.), Linguistic theory and language development in Hispanic languages (pp. 375-397). Somerville, MA: Cascadilla Press.

Terrell, T. D., Baycroft, B., \& Perrone, C. (1987). The subjunctive in Spanish interlanguage: Accuracy and comprehensibility. In B. VanPatten, T. R. Dvorak \& J. F. Lee (Eds.), Foreign language learning: A research perspective (pp. 19-32). Cambridge: Newbury House Publishers.

Teschner, R. V. (1981). Spanish for native speakers: Evaluating twenty-five Chicano compositions in a first-year course. In G. Valdés, A. G. Lozano \& R. GarciaMoya (Eds.), Teaching Spanish to the Hispanic bilingual: Issues, aims, and methods (pp. 115-139). New York: Teachers College Press.

U.S. Census Bureau. (2004). [Press release June 14, 2004] Hispanic and Asian

Americans increasing faster than overall population. U.S. Census Bureau.

Retrieved from http://www.census.gov/Press-

Release/www/releases/archives/race/001839.html

Valdés, G. (2001). Heritage language students: Profiles and possibilities. In J. Kreeft. Peyton, D. A. Ranard \& S. McGinnis (Eds.), Heritage languages in America: Preserving a national resource (pp. 37-77). Washington, DC: Center for Applied Linguistics; Educational Resources Information Center; McHenry, IL: Delta Systems Co.

Valdés, G. (2005). Bilingualism, heritage language learners, and SLA research: Opportunities lost or seized? Modern Language Journal, 89(3), 410-426.

Valdés, G., Fishman, J. A., Chávez, R., \& Pérez, W. (2006). Developing minority language resources: The case of Spanish in California. Clevedon, UK: Multilingual Matters.

Zentella, A. C. (1997). Growing up bilingual. Malden: Blackwell.

\section{Notes}

\footnotetext{
${ }^{1}$ Analyses that used listwise deletion and scoring non-responses as non-native-like to deal with missing observations yielded the same substantive results: no significant differences were found between early and late childhood bilinguals. Moreover, alternate analyses that grouped the young adult bilinguals with the late childhood bilinguals using each of the missing data techniques also failed to produce any significant differences between this combined group and early childhood bilinguals on task and combined scores. (back)
} 


\begin{abstract}
${ }^{2}$ Another set of alternate analyses included the 12 participants (10 early childhood bilinguals and 2 late childhood bilinguals) who scored less than 6 out of 7 points on the cloze task. The substantive results were the same, with no significant differences between early and late childhood bilinguals. (back)

3 These scores were within the range of scores obtained for the early and late childhood bilinguals using all three missing data techniques. Depending on the technique used, the young adult bilingual scores were either closer to those of the early childhood bilinguals or those of the late childhood bilinguals. (back)
\end{abstract}

${ }^{4}$ The results of the multivariate analyses were very similar when participants who scored less than 6 points on the cloze task were included. Multiple trips abroad were associated with higher editing and combined scores $(\mathrm{p}=0.046$ and $\mathrm{p}=0.031$, respectively). There was also a significant relationship between predominant use of Spanish at home in the past and higher editing task scores $(p=0.005)$. No significant relationships were found between formal instruction and individual task and combined scores. (back)

${ }^{5}$ Alternate analyses were performed in which early childhood bilinguals were defined as those who were born in the U.S. $(n=19)$ and late childhood bilinguals were those who were born elsewhere but immigrated between the ages of 3 and 13 ( $n=11$; the 2 young adult bilinguals were not included in this group, and none of the foreign-born participants immigrated before age 3). These analyses showed no significant difference between groups on the individual tasks and the combined scores. (back) 